\title{
Contralateral prophylactic mastectomy in young women with breast cancer: a population-based analysis of predictive factors and clinical impact
}

\author{
A. Bouchard-Fortier MD MSc, * N.N. Baxter MD PhD, ${ }^{\dagger \neq}$ R. Sutradhar PhD, ${ }^{\S}$ K. Fernandes MSc, $\$$ \\ X. Camacho MSc, $\$$ P. Graham MD, ${ }^{*}$ and M.L. Quan MD MSc*
}

\begin{abstract}
Background and Objectives Contralateral prophylactic mastectomy (CPM) has been increasingly common among women with unilateral invasive breast cancer (івса) even though the data that support it are limited. Using a population-based cohort, the objectives of the present study were to describe factors predictive of CPM in young women ( $\leq 35$ years) with івса and to evaluate the impact of the procedure on mortality.
\end{abstract}

Methods All women diagnosed during 1994-2003 and treated with CPM were identified from the Ontario Cancer Registry. Logistic regression was used to identify patient and tumour factors associated with the use of CPM. Multivariate analyses were used to assess the effect of CPM on recurrence and mortality.

Results Of 614 women identified, 81 underwent CPM (13.2\%). On multivariable analysis, factors associated with CPM included negative lymph node status, negative estrogen receptor status, and initial breast-conserving surgery with re-excision. At follow-up, breast cancer-specific mortality was similar for women who did and did not undergo CPM.

Conclusions Use of СРм in young women with iвса (compared with non-use) was not associated improved breast cancer-specific mortality. Factors found to be predictive of CPM were negative lymph node status, negative estrogen receptor status, and initial breast-conserving surgery followed by re-excision.

Key Words Contralateral prophylactic mastectomy, breast cancer, young women

Curr Oncol. 2018 Dec;25(6):e562-e568

www.current-oncology.com

\section{INTRODUCTION}

Breast cancer (вСа) is one of the most commonly diagnosed cancers worldwide and the most frequent malignancy in women $^{1}$. Since the late 1980 s, surgery for Bca has moved away from the modified radical mastectomy to much less invasive procedures such as breast-conserving surgery (всs) combined with sentinel lymph node biopsy. However, more recently, the trend has, despite the lack of a proven survival benefit, reversed toward more invasive procedures such as mastectomy combined with contralateral prophylactic mastectomy (СРM). Indeed, rates of СРм in women with invasive вса (івса) have increased more than $150 \%$ in North America since about $2009^{2-4}$. Although CPM is associated with a reduction in the incidence of contralateral $\mathrm{BCa}^{5-9}$, studies evaluating the impact of CPM on mortality have produced conflicting results ${ }^{2,5-12}$. The only studies in which a survival benefit of CPM was demonstrated involved groups of patients at significant risk of bilateral BCa-specifically, patients with BRCA1 and BRCA2 mutations ${ }^{2,13}$.

Breast cancer is uncommon in young women $(\leq 35$ years). Such patients constitute just a small fraction $(<3 \%)$ of all patients diagnosed with the disease, and they are more likely to undergo $\mathrm{CPM}^{14-16}$. Because younger women are generally underrepresented in studies evaluating the use of СРM, little is known about the factors predictive of its use in that group and whether a reduction in mortality is associated with the procedure in this higher-risk population. 
In the present study, we aimed to describe factors predictive of СРM in very young women ( $\leq 35$ years) with iвca and to evaluate the impact of СРм on recurrence and BCa-specific mortality.

\section{METHODS}

\section{Patients}

Patients for the study were identified from the Ontario Cancer Registry, a provincial registry that records all patients with incident cancers diagnosed in the province of Ontario since 1964. Reporting cancer cases to the Ontario Cancer Registry is provincially mandated, and the data are estimated to be $95 \%$ complete $^{17}$. All women diagnosed with unilateral iвса (code 174, International Classification of Diseases, Ninth Revision), 35 years of age or younger in Ontario between 1994 and 2003 were identified in the Ontario Cancer Registry. Patients who did not undergo mastectomy for their вса, those with a previous diagnosis of a noncutaneous malignancy, and those with evidence of stage IV disease within 6 months of diagnosis were excluded.

Patient demographics, treatment characteristics [including type of surgery (unilateral or bilateral mastectomy), final pathology, adjuvant treatments (chemotherapy, radiation), and side of $\mathrm{BCa}$, and recurrence and death were abstracted in a primary chart review as previously described $^{18}$. Contralateral prophylactic mastectomy was defined as prophylactic mastectomy of the contralateral breast performed within 1 year of the initial primary breast surgery. Patients initially treated with всs were included in the analysis if re-excision with a mastectomy was performed within 1 year after the BCs.

This study was approved by the Sunnybrook Health Sciences research ethics review board and the research ethics board or equivalent at each treating hospital.

\section{Exposure}

The main exposure was the use of CPM (yes or no) in patients with івса treated with mastectomy. We were interested in examining the factors associated with CPM as relationships between the type of surgery and the risk of recurrence (local, regional, or distant) and вса-specific mortality. We identified these covariates for our analysis: age at diagnosis, neoadjuvant chemotherapy (yes or no), tumour size ( 0 to $<20 \mathrm{~mm}, 20 \mathrm{~mm}$ to $<50 \mathrm{~mm}, \geq 50 \mathrm{~mm}$ ), multifocality (yes or no), multicentricity (yes or no), Bcs followed by mastectomy compared with mastectomy as the initial procedure, number of positive nodes $(0,1-3, \geq 4)$, primary histologic type (ductal, lobular, mixed, or other), grade (I, II, or III), presence of lymphovascular invasion [LVI (yes or no)], estrogen receptor (ER) status (negative or positive), progesterone receptor status (negative or positive), use of adjuvant chemotherapy (yes or no), use of adjuvant radiation (yes or no), and reconstruction (yes or no).

\section{Outcome}

Outcomes included recurrences, all-cause mortality, and BCa-specific mortality. For the analysis of CPM predictors, CPM was also considered to be an outcome. Time to first recurrence was defined as the interval from the diagnosis date to the date of any recurrence. Deaths were obtained from the Office of the Registrar General-Deaths dataset. All-cause mortality was calculated from the time of вса diagnosis to death from any cause. The Bca-specific mortality was calculated from the time of вса diagnosis to death caused by вса. Patients were followed until their first event date or 15 November 2011.

\section{Statistical Analysis}

Baseline characteristics of the patients with and without CPM were compared using the chi-square test for categorical variables and the $t$-test for continuous variables. Logistic regression was used to evaluate patient and tumour factors associated with the use of CPM. The Kaplan-Meier method with log-rank test was used to compared Bca-specific mortality between patients with and without CPM. Cox proportional hazards models were used to examine the association between СРм performance and вса-specific mortality. The models were adjusted for patient, tumour, and treatment characteristics (age, neoadjuvant chemotherapy, всs followed by re-excision, multifocality, multicentricity, size of primary tumour, total number of involved lymph nodes, LVI, primary histologic type, pathologic subtype, ER and progesterone receptor status, adjuvant chemotherapy, and adjuvant radiation therapy). Variables were assessed for multi-collinearity by examining their variance inflation factors. A variance inflation factor greater than 10 was accepted a suggesting multi-collinearity. The association between CPM performance and вса recurrence was examined by treating death from any cause as a competing risk using causespecific regression models and the Fine and Gray approach ${ }^{19}$. All statistical analyses were 2-sided and a $p$ value of 0.05 or less was considered statistically significant. The SAS Enterprise Guide software application (version 6.1: SAS Institute, Cary, NC, U.S.A.) was used for the statistical analyses.

\section{RESULTS}

Of 614 women identified for the present study, 81 (13.2\%) had undergone СРM; the remaining 533 (86.8\%) had not. Table I shows patient, tumour, and treatment characteristics by receipt of CPM. In patients undergoing CPM, tumour size was significantly smaller ( $p=0.01)$, LVI was less likely ( $p=0.003)$, fewer axillary lymph nodes were positive $(p<0.001)$, and the rate of ER-negativity was higher $(p=$ $0.01)$. In addition, compared with patients who did not undergo СРM, more of those who underwent СРм had a surgical re-excision after a first attempt at всs $(p<0.001)$, and more underwent reconstructive surgery $(p<0.001)$.

On multivariable analysis, factors significantly associated with the use of CPM were negative nodal status [odds ratio (OR): 2.46 ; $95 \%$ confidence interval (CI): 1.31 to 4.62 ; $p=0.005$ ], ER negativity (OR: 2.57 ; $95 \%$ CI: 1.20 to $5.53 ; p=$ 0.02), and initial BCs with re-excision (oR: 3.09; 95\% CI: 1.57 to $6.10 ; p=0.001$; Table II).

After a median follow-up of 11 years, 308 patients $(50.2 \%)$ sustained a recurrence, with the most common recurrence location being distant $(46.4 \%)$. Recurrences were significantly fewer for patients with CPM than for those without (32.1\% vs. 52.9\%, $p<0.001$, Table III). The Fine and Grey approach describes relative risks between groups. The risk of recurrence was lower in the СРм group than in the 
TABLE I Patient characteristics

\begin{tabular}{|c|c|c|}
\hline \multirow[t]{2}{*}{ Characteristic } & \multicolumn{2}{|c|}{$\begin{array}{c}\text { Contralateral prophylactic } \\
\text { mastectomy }\end{array}$} \\
\hline & Yes & No \\
\hline Patients ( $n)$ & 81 & 533 \\
\hline Mean age (years) & $31.58 \pm 3.17$ & $32.18 \pm 2.71$ \\
\hline \multicolumn{3}{|l|}{ Neoadjuvant CTx [n(\%)] } \\
\hline No & $71(87.7)$ & $444(83.3)$ \\
\hline Yes & $10(12.3)$ & $89(16.7)$ \\
\hline \multicolumn{3}{|l|}{ Tumour size at $S x[n(\%)]$} \\
\hline$\leq 20 \mathrm{~mm}$ & $31(38.3)$ & $123(23.1)$ \\
\hline $21-50 \mathrm{~mm}$ & $34(42.0)$ & $260(48.8)$ \\
\hline$>50 \mathrm{~mm}$ or missing ${ }^{\mathrm{a}}$ & $16(19.8)$ & $150(28.1)$ \\
\hline \multicolumn{3}{|l|}{ Multifocality $[n(\%)]$} \\
\hline No & $54(66.7)$ & $348(65.3)$ \\
\hline Yes & $27(33.3)$ & $185(34.7)$ \\
\hline \multicolumn{3}{|l|}{ Multicentricity $[n(\%)]$} \\
\hline No & $75(92.6)$ & $497(93.2)$ \\
\hline Yes & $6(7.4)$ & $36(6.8)$ \\
\hline \multicolumn{3}{|l|}{ Node-positive status [n (\%)] } \\
\hline 0 & $42(51.9)$ & $144(27.0)$ \\
\hline $1-3$ & $18(22.2)$ & $148(27.8)$ \\
\hline$>3$ & $9(11.1)$ & $168(31.5)$ \\
\hline Not investigated or missing & $12(14.8)$ & $73(13.7)$ \\
\hline \multicolumn{3}{|c|}{ Re-excision Sx after initial BCS $[n(\%)]$} \\
\hline No & $61(75.3)$ & $492(92.3)$ \\
\hline Yes & $20(24.7)$ & $41(7.7)$ \\
\hline \multicolumn{3}{|c|}{ Breast reconstructive surgery $[n(\%)]$} \\
\hline No & $22(27.2)$ & $370(69.4)$ \\
\hline Yes & $59(72.8)$ & $163(30.6)$ \\
\hline \multicolumn{3}{|l|}{ Receptor status $[n(\%)]$} \\
\hline ER-negative & $48(59.3)$ & $221(41.5)$ \\
\hline ER-positive & $\leq 30$ & $257(48.2)$ \\
\hline ER missing & $\leq 5$ & $55(10.3)$ \\
\hline PgR-negative & $40(49.4)$ & $239(44.8)$ \\
\hline PgR-positive & $34(42.0)$ & $233(43.7)$ \\
\hline PgR missing & $7(8.6)$ & $61(11.4)$ \\
\hline \multicolumn{3}{|l|}{ Lymphovascular invasion [n (\%)] } \\
\hline No & $33(40.7)$ & $159(29.8)$ \\
\hline Yes & $27(33.3)$ & $284(53.5)$ \\
\hline Missing & $21(25.9)$ & $90(16.9)$ \\
\hline \multicolumn{3}{|l|}{ Histologic grade $[n(\%)]$} \\
\hline $\mathrm{I} / \mathrm{II}$ & $22(27.2)$ & $173(32.5)$ \\
\hline III & $51(63.0)$ & $297(55.7)$ \\
\hline Missing & $8(9.9)$ & $63(11.8)$ \\
\hline \multicolumn{3}{|l|}{ Pathologic subtype $[n(\%)]$} \\
\hline Ductal & $26(32.1)$ & $206(38.6)$ \\
\hline Mixed or lobular & $45(55.6)$ & $274(51.4)$ \\
\hline Missing ${ }^{\mathrm{a}}$ or other & $10(12.3)$ & $53(9.9)$ \\
\hline
\end{tabular}

\begin{tabular}{lll}
\hline $\begin{array}{l}\text { Adjuvant chemotherapy }[n(\%)] \\
\text { No }\end{array}$ & $21(25.9)$ & $142(26.6)$ \\
Yes & $60(74.1)$ & $391(73.4)$ \\
Adjuvant radiation & & \\
$\quad$ No or missing & & \\
$\quad$ Yes & $38(53.1)$ & $245(46.0)$ \\
Hormonal therapy & & \\
(patients positive for ER or PgR) & & \\
$\quad$ Medical & $16(42.1)$ & $136(48.1)$ \\
$\quad$ Medical or surgical & $10(26.3)$ & $21(7.4)$ \\
None or missing & $12(31.6)$ & $126(44.5)$ \\
\hline
\end{tabular}

a "Missing" category was combined with another variable when it included 5 or fewer patients.

$\mathrm{CTx}=$ chemotherapy; $\mathrm{Sx}=$ surgery; $\mathrm{BCS}$ = breast-conserving surgery; $\mathrm{ER}=$ estrogen receptor; $\mathrm{PgR}=$ progesterone receptor.

TABLE II Multivariate analysis of factors associated with the use of contralateral prophylactic mastectomy

\begin{tabular}{|c|c|c|c|}
\hline Variable & Adjusted OR & $95 \% \mathrm{Cl}$ & $p$ Value \\
\hline Age & 0.94 & 0.86 to 1.03 & 0.18 \\
\hline Neoadjuvant CTx & 1.05 & 0.43 to 2.59 & 0.92 \\
\hline \multicolumn{4}{|l|}{ Tumour size } \\
\hline$\leq 20 \mathrm{~mm}$ & \multicolumn{2}{|c|}{ Reference } & \\
\hline $21-50 \mathrm{~mm}$ & 0.62 & 0.34 to 1.13 & 0.12 \\
\hline$>50 \mathrm{~mm}$ & 0.78 & 0.35 to 1.74 & 0.54 \\
\hline Node-negative & 2.46 & 1.31 to 4.62 & 0.005 \\
\hline ER-negative & 2.57 & 1.20 to 5.53 & 0.02 \\
\hline PgR-negative & 0.51 & 0.24 to 1.10 & 0.08 \\
\hline LVI-positive & 0.70 & 0.37 to 1.35 & 0.29 \\
\hline \multicolumn{4}{|l|}{ Grade } \\
\hline I & \multicolumn{2}{|c|}{ Reference } & \\
\hline II & 1.42 & 0.36 to 5.60 & 0.62 \\
\hline III & 1.85 & 0.47 to 7.22 & 0.38 \\
\hline Multicentricity & 0.88 & 0.49 to 1.58 & 0.66 \\
\hline Multifocality & 0.88 & 0.48 to 1.58 & 0.66 \\
\hline Adjuvant CTx & 1.32 & 0.64 to 2.69 & 0.45 \\
\hline Adjuvant radiation & 0.92 & 0.53 to 1.62 & 0.78 \\
\hline Re-excision surgery & 2.70 & 1.51 to 4.71 & 0.0007 \\
\hline
\end{tabular}

$\mathrm{OR}=$ odds ratio; $\mathrm{Cl}=$ confidence interval $; \mathrm{CTx}=$ chemotherapy $; \mathrm{ER}=$ estrogen receptor; $\mathrm{PgR}=$ progesterone receptor; $\mathrm{LVI}=$ lymphovascular invasion.

no-СРM group, and that relative difference was statistically significant [hazard ratio (HR): $0.61 ; p=0.02$; Table IV].

Overall, 240 deaths occurred, of which 228 (95\%) were attributable to вса. On univariate analysis, вса-specific mortality was lower for patients who had undergone CPM than for those who had not ( $19.5 \%$ vs. $40.0 \%$, Table III). However, those findings were not found to be significant in multivariate analysis (HR: 0.73 ; $95 \%$ cr: 0.47 to $1.21 ; p=0.22$; Table v). The competing-risks analyses also found no significant difference in the risk of death between the CPM and no-СPM groups (Table v). 


\section{DISCUSSION}

In the present study, we evaluated factors associated with the use of СPM and the association of СРM with recurrence

TABLE III Recurrence and breast cancer (BCa)-specific mortality in patients treated with mastectomy with or without contralateral prophylactic mastectomy

\begin{tabular}{lcc}
\hline \multicolumn{1}{c}{ Variable } & \multicolumn{2}{c}{ Contralateral prophylactic mastectomy } \\
\cline { 2 - 3 } & No & Yes \\
\hline Patients $(n)$ & 81 & 533 \\
BCa recurrence $[n(\%)]$ & & \\
No & $55(67.9)$ & $251(47.1)$ \\
Yes & $26(32.1)$ & $282(52.9)$ \\
Recurrence location $[n(\%)]$ & & \\
Local & $\leq 5$ & $52(17.7)$ \\
Regional & $6(23.1)$ & $28(9.9)$ \\
Contralateral & $\leq 5$ & $132(46.8)$ \\
Distant & $11(42.3)$ & $20(7.1)$ \\
Missing & $\leq 5$ & $322(60.4)$ \\
BCa-specific death & & $211(39.6)$ \\
No & $64(79.0)$ & $310(58.2)$ \\
Yes & $17(21.0)$ & $223(41.8)$ \\
Death (to 15 Nov 2011) & & \\
No & $64(79.0)$ & $17(21.0)$ \\
Yes & & \\
\hline
\end{tabular}

and вса-specific mortality in a large population-based cohort of very young women. In adjusted analyses, we found that node negativity, ER negativity, and initial BCs followed by re-excision were associated with increased use of CPM. After a median of 11 years of follow-up, the rate of вса recurrence was found to be significantly lower in CPM patients in both the Fine and Grey and cause-specific models. However, no significant improvement in Bca-specific mortality was observed between women who underwent CPM and those who did not.

Several other studies have identified various patientand tumour-related factors associated with the use of $\mathrm{CPM}^{5,16,20-23}$. Factors reportedly associated with CPM include white race, married status, a higher education, and a positive family history of вса-variables that we were unable to collect for our cohort. We did find that a prior attempt at BCs and the use of reconstructive surgery were more common in the CPM group. A prior attempt at BCs could have resulted in the patient experiencing increased anxiety when repeat surgery was needed for positive margins after the всs. Failure to achieve negative margins with BCs is an indication for mastectomy and could have influenced women to opt for the most radical treatment, including CPM, given a perceived "failure" of initial attempts at BCS. Similar findings were demonstrated by King et al. ${ }^{20}$, who revealed that a prior attempt at breast conservation was an independent predictor of CPM (OR: 1.7). The use of reconstructive surgery has also been reported to be associated with performance of СPM. Our findings support those from Hoskin et al. ${ }^{21}$, who found that, compared with patients who did not undergo immediate breast reconstruction, those who did were 2.7 times more likely to have a CPM.

TABLE IV Crude and adjusted hazard ratios (HRs) for recurrence and death, Fine and Gray model ${ }^{\mathrm{a}}$

\begin{tabular}{|c|c|c|c|c|c|c|c|c|}
\hline \multirow[t]{2}{*}{ Variable } & \multicolumn{4}{|c|}{ Fine and Gray HR } & \multicolumn{4}{|c|}{ Cause-specific HR } \\
\hline & Crude & $p$ Value & Adjusted $^{\mathbf{b}}$ & $p$ Value & Crude & $p$ Value & Adjusted & $p$ Value \\
\hline \multicolumn{9}{|l|}{ Recurrence } \\
\hline CPM & 0.51 & 0.001 & 0.61 & 0.02 & 0.51 & 0.001 & 0.62 & 0.03 \\
\hline No CPM & \multicolumn{4}{|c|}{ Reference } & \multicolumn{4}{|c|}{ Reference } \\
\hline \multicolumn{9}{|l|}{ Death } \\
\hline CPM & 0.95 & 0.95 & 1.36 & 0.77 & 0.77 & 0.73 & 1.39 & 0.71 \\
\hline No CPM & \multicolumn{4}{|c|}{ Reference } & \multicolumn{4}{|c|}{ Reference } \\
\hline
\end{tabular}

a Censored: 299; recurrence: 299; death: 16 .

b Adjusted for patient, tumour and treatment characteristics (age, neoadjuvant chemotherapy, breast-conserving surgery followed by re-excision, multifocality, multicentricity, size of primary tumour, total number of involved lymph nodes, lymphovascular invasion, primary histologic type, pathologic subtype, estrogen and progesterone receptor status, adjuvant chemotherapy, and adjuvant radiation therapy).

$\mathrm{CPM}=$ contralateral prophylactic mastectomy.

TABLE V Multivariate analysis of breast cancer-specific mortality by use of contralateral prophylactic mastectomy (CPM)

\begin{tabular}{|c|c|c|c|c|c|c|}
\hline Exposure & Crude HR & $95 \% \mathrm{Cl}$ & p Value & Adjusted $\mathbf{H R}^{\mathrm{a}}$ & $95 \% \mathrm{Cl}$ & $p$ Value \\
\hline CPM & 0.55 & 0.34 to 0.90 & 0.02 & 0.73 & 0.44 to 1.21 & 0.22 \\
\hline No CPM & \multicolumn{3}{|c|}{ Reference } & \multicolumn{2}{|c|}{ Reference } & \\
\hline
\end{tabular}


That observation can probably be explained by a desire to achieve symmetry with reconstruction. In addition, in Canada, reconstructive surgery associated with вса treatment is funded by the government; the availability or affordability of reconstructive surgery would therefore not be a factor in our cohort.

Very young age has been found to be associated with poorer outcomes and, in stage-for-stage comparisons with older age groups, is considered an independent predictor of recurrence and death ${ }^{18,24-30}$. However, we found that patients undergoing СРм had better disease prognosis, including smaller tumours with no LVI and node negativity. Other studies have reported similar use of СРM in patients with "low risk" disease having characteristics such as low grade, node negativity, and lobular histology $\mathrm{y}^{5,15-16,20,22-23}$. Those findings might suggest that patient preference plays a strong role in the decision-making process for a СРM, with patients having "low risk" disease feeling the most threatened by a possible metachronous cancer in the contralateral breast.

The effect of CPM on survival has been studied with mixed results. Two potential explanations have been offered for the observed increased survival or survival trend associated with the use of CPM. First, CPM could prevent a contralateral cancer that would eventually cause death. A recent analysis of U.S. Surveillance, Epidemiology, and End Results data by Kruper et al. in 2014 that included 26,526 patients with вса undergoing СРм revealed that, compared with no CPM, CPM was associated with improved disease-specific survival (HR: 0.86 ; $95 \%$ CI: 0.79 to 0.93 ) and overall survival [os (HR: 0.76 ; $95 \%$ CI: 0.71 to 0.81 )] ${ }^{7}$. The authors repeated the analysis by removing the women with contralateral вса who had been treated without СРM and found little impact on the rate of disease-specific survival or of os, suggesting that CPM could not explain the survival benefit and that the results most likely reflected selection bias in the patients opting for CPM. In addition, Fayanju et $a l .^{2}$, who in 2014 published a meta-analysis of 14 observational and retrospective studies, found that recipients of CPM experienced a higher rate of os (relative risk: 1.09; $95 \%$ CI: 1.06 to 1.11) and a lower rate of вса-specific mortality (relative risk: $0.69 ; 95 \% \mathrm{CI}: 0.56$ to 0.85 ), but saw no absolute reduction in the risk of metachronous contralateral вса. An analysis of U.S. Surveillance, Epidemiology, and End Results data by Bedrosian et al. ${ }^{9}$, evaluating the effect of CPM on survival, found a small benefit in young women with ER-negative disease. The authors hypothesized that the benefit was related to a reduction in the higher baseline risk of contralateral вса associated with ER-negative disease. (Risk of contralateral BCa is reduced in ER-positive women receiving long-term hormonal treatment.)

Although we found an association of ER-negative disease and CPM, we did not find a survival benefit in our study, which might be an issue of sample size. A second explanation supported by the more favourable tumour characteristics found in our study and others, is that the patient population opting for a СРM are at a lower risk of dying from Bca than their counterparts (that is, selection bias). A subset analysis looking at patients with elevated familial or genetic risk (BRCA carrier status or a family history of $\mathrm{BCa}$, or both) found that the relative and absolute risks of metachronous contralateral вса were both significantly lower for СРМ recipients (relative risk: 0.04; 95\% CI: 0.02 to 0.09 ), but without improvement in os. The authors concluded that the superior outcomes observed in women having CPM were probably attributable to selection bias, given that no decrease in contralateral disease was observed. Findings from both series are consistent with our own results suggesting that women undergoing СРM have more favourable tumours and overall prognosis.

It is possible that patients at significantly higher risk of contralateral disease, such as mutation carriers, might realize a survival benefit. Metcalfe et al. ${ }^{13}$ looked at the effect of contralateral mastectomy in patients with BRCA1 and $B R C A 2$ mutations, finding that contralateral mastectomy in that population was associated with a $48 \%$ reduction in death from вса over a 20 -year period. The authors concluded that the survival benefit was obtained by preventing the occurrence of a cancer in the contralateral breast that would have eventually affected survival.

Recently, the American Society of Breast Surgeons published a consensus statement about the use of CPM $^{3}$. Based on the available evidence, they recommend considering CPM in women with a significant risk of contralateral івса-for example, patients with BRCA1/2 mutations, patients with $25 \%$ or greater estimated lifetime risk of iвca, and patients with a history of mantle field radiation to the chest before the age of 30 . The authors concluded that no survival benefit accrued to the performance of CPM in average-risk individuals and that surgical complications were double those for unilateral mastectomy.

The present study has numerous strengths. It represents the largest population-based analysis of young women 35 years of age and younger treated for BCa that has robust patient-level data and long-term follow-up. Of the 614 identified patients, none were lost to follow-up. The cause of death was known for all deceased patients, and very few variables were missing. Inherent limitations include the study's retrospective design and its relatively small sample size, which could have limited the power to identify potential small survival benefits in certain subgroups of patients. In addition, we were unable to control for important confounders such as BRCA status, HER2 status, and family history of вса (variables unavailable). Positivity for the HER2 receptor can occur in $10 \%-15 \%$ of young patients with вса $^{31}$. An imbalance in HER2 positivity between the two groups could have influenced results in a certain direction, given that patients who are HER2-positive have higher recurrence rates and mortality. Similarly, the $B R C A$ status in our cohort was unknown. Metcalfe's finding of improved survival in mutation carriers could have biased results in favour of CPM. Overall, those limitations are unlikely to have substantially influenced the results of the study. In addition, our study is, like others, limited by not knowing the actual reason that each woman was treated with СРм; clearly, the decision is multifactorial and is likely to reflect perception of a combination of oncologic, esthetic, and psychological benefits.

\section{CONCLUSIONS}

In summary, СРм is not associated with improved вса mortality in young women with вса. Node-negative disease, 
ER negativity, and initial BCs followed by re-excision were predictors of CPM. Further studies with larger sample sizes and longer follow-up are warranted to ascertain if a survival benefit accrues to certain subgroups of young women with вса. Overall, the decision to perform СPм should be individualized according to patient preference and the long-term risk of а вса developing in the contralateral breast.

\section{ACKNOWLEDGMENTS}

This study was supported by the Institute for Clinical Evaluative Sciences (ICES), which is funded by an annual grant from the Ontario Ministry of Health and Long-Term Care (монцтс). The opinions, results, and conclusions reported in this paper are those of the authors and are independent from the funding sources. No endorsement by ices or the Ontario MoнLtc is intended or should be inferred. Parts of this material are based on data and information provided by Cancer Care Ontario (cco). The opinions, results, views, and conclusions reported in this paper are those of the authors and do not necessarily reflect those of cco. No endorsement by cco is intended or should be inferred. Parts of this material are based on data and information compiled and provided by the Canadian Institute for Health Information (сіні). However, the analyses, conclusions, opinions, and statements expressed herein are those of the authors, and not necessarily those of CIHI.

\section{CONFLICT OF INTEREST DISCLOSURES}

We have read and understood Current Oncology's policy on disclosing conflicts of interest, and we declare that we have none.

\section{AUTHOR AFFILIATIONS}

*Division of Surgical Oncology, University of Calgary, Calgary, AB; ${ }^{\dagger}$ Department of Surgery and ${ }^{\ddagger}$ Dalla Lana School of Public Health, University of Toronto, and ${ }^{\S}$ Institute for Clinical Evaluative Sciences, Toronto, ON.

\section{REFERENCES}

1. International Agency for Research on Cancer (IARC). Breast [fact sheet]. Lyon, France: IARC; 2018. [Available online at: http://gco.iarc.fr/today/data/factsheets/cancers/20-Breastfact-sheet.pdf; cited 26 October 2018]

2. Fayanju OM, Stoll CR, Fowler S, Colditz GA, Margenthaler JA. Contralateral prophylactic mastectomy after unilateral breast cancer: a systematic review and meta-analysis. Ann Surg 2014;260:1000-10.

3. Boughey JC, Attai DJ, Chen SL, et al. Contralateral prophylactic mastectomy (СРM) consensus statement from the American Society of Breast Surgeons: data on сPM outcomes and risks. Ann Surg Oncol 2016;23:3100-5.

4. Jones NB, Wilson J, Kotur L, Stephens J, Farrar WB, Agnese DM. Contralateral prophylactic mastectomy for unilateral breast cancer: an increasing trend at a single institution. Ann Surg Oncol 2009;16:2691-6.

5. Peralta EA, Ellenhorn JD, Wagman LD, Dagis A, Andersen JS, Chu DZ. Contralateral prophylactic mastectomy improves the outcome of selected patients undergoing mastectomy for breast cancer. Am J Surg 2000;180:439-45.

6. McDonnell SK, Schaid DJ, Myers JL, et al. Efficacy of contralateral prophylactic mastectomy in women with a personal and family history of breast cancer. JClin Oncol 2001;19:3938-43.

7. Kruper L, Kauffmann RM, Smith DD, Nelson RA. Survival analysis of contralateral prophylactic mastectomy: a question of selection bias. Ann Surg Oncol 2014;21:3448-56.

8. Herrinton LJ, Barlow WE, Yu O, et al. Efficacy of prophylactic mastectomy in women with unilateral breast cancer: a cancer research network project. J Clin Oncol 2005;23:4275-86.
9. Bedrosian I, Hu CY, Chang GJ. Population-based study of contralateral prophylactic mastectomy and survival outcomes of breast cancer patients. J Natl Cancer Inst 2010;102:401-9.

10. Zeichner SB, Zeichner SB, Ruiz AL, Markward NJ, Rodriguez E. Improved long-term survival with contralateral prophylactic mastectomy among young women. Asian PacJ Cancer Prev 2014;15:1155-62.

11. Pesce C, Liederbach E, Wang C, Lapin B, Winchester DJ, Yao K. Contralateral prophylactic mastectomy provides no survival benefit in young women with estrogen receptornegative breast cancer. Ann Surg Oncol 2014;21:3231-9.

12. Kurian AW, Lichtensztajn DY, Keegan TH, Nelson DO, Clarke CA, Gomez SL. Use of and mortality after bilateral mastectomy compared with other surgical treatments for breast cancer in California, 1998-2011. JAMA 2014;312:902-14.

13. Metcalfe K, Gershman S, Ghadirian P, et al. Contralateral mastectomy and survival after breast cancer in carriers of $B R C A 1$ and BRCA2 mutations: retrospective analysis. BMJ 2014;348:g226.

14. Cancer Society's Steering Committee on Cancer Statistics. Canadian Cancer Statistics 2012. Toronto, ON: Canadian Cancer Society; 2012.

15. Yao K, Stewart AK, Winchester DJ, Winchester DP. Trends in contralateral prophylactic mastectomy for unilateral cancer: a report from the National Cancer Data Base, 1998-2007. Ann Surg Oncol 2010;17:2554-62.

16. Tracy MS, Rosenberg SM, Dominici L, Partridge AH. Contralateral prophylactic mastectomy in women with breast cancer: trends, predictors, and areas for future research. Breast Cancer Res Treat 2013;140:447-52.

17. Robles SC, Marrett LD, Clarke EA, Risch HA. An application of capture-recapture methods to the estimation of completeness of cancer registration. J Clin Epidemiol 1988;41:495-501.

18. Quan ML, Osman F, McCready D, Fernandes K, Sutradhar $\mathrm{R}$, Paszat L. Postmastectomy radiation and recurrence patterns in breast cancer patients younger than age 35 years: a population-based cohort. Ann Surg Oncol 2014;21:395-400.

19. Austin PC, Lee DS, Fine JP. Introduction to the analysis of survival data in the presence of competing risks. Circulation 2016;133:601-9.

20. King TA, Sakr R, Patil S, et al. Clinical management factors contribute to the decision for contralateral prophylactic mastectomy. J Clin Oncol 2011;29:2158-64.

21. Hoskin TL, Hieken TJ, Degnim AC, Jakub JW, Jacobson SR, Boughey JC. Use of immediate breast reconstruction and choice for contralateral prophylactic mastectomy. Surgery 2016;159:1199-209.

22. Arrington AK, Jarosek SL, Virnig BA, Habermann EB, Tuttle TM. Patient and surgeon characteristics associated with increased use of contralateral prophylactic mastectomy in patients with breast cancer. Ann Surg Oncol 2009;16:2697704.

23. Yi M, Hunt KK, Arun BK, et al. Factors affecting the decision of breast cancer patients to undergo contralateral prophylactic mastectomy. Cancer Prev Res (Phila) 2010;3:1026-34.

24. De la Rochefordiere A, Asselain B, Campana F, et al. Age as prognostic factor in premenopausal breast carcinoma. Lancet 1993;341:1039-43.

25. Walker RA, Lees E, Webb MB, Dearing SJ. Breast carcinomas occurring in young women ( $<35$ years) are different. $\mathrm{Br} J$ Cancer 1996;74:1796-800.

26. Kim SH, Simkovich-Heerdt A, Tran KN, Maclean B, Borgen PI. Women 35 years of age or younger have higher locoregional relapse rates after undergoing breast conservation therapy. J Am Coll Surg 1998;187:1-8. 
27. Xiong Q, Valero V, Kau V, et al. Female patients with breast carcinoma age 30 years and younger have a poor prognosis: the M.D. Anderson Cancer Center experience. Cancer 2001;92:2523-8.

28. Voogd AC, Nielsen M, Peterse JL, et al. on behalf of the Danish Breast Cancer Cooperative Group and the Breast Cancer Cooperative Group of the European Organization for Research and Treatment of Cancer. Differences in risk factors for local and distant recurrence after breast-conserving therapy or mastectomy for stage I and II breast cancer: pooled results of two large European randomized trials. JClin Oncol2001;19:1688-97. [Erratum in: J Clin Oncol 2001;19:2583]
29. Han W, Kim SW, Park IA, et al. Young age: an independent risk factor for disease-free survival in women with operable breast cancer. BMC Cancer 2004;4:82.

30. Bollet MA, Sigal-Zafrani B, Mazeau V, et al. Age remains the first prognostic factor for loco-regional breast cancer recurrence in young ( $<40$ years) women treated with breast conserving surgery first. Radiother Oncol 2007;82:272-80.

31. Wang K, Ren Y, Li H, et al. Comparison of clinicopathological features and treatments between young ( $\leq 40$ years) and older ( $>40$ years) female breast cancer patients in West China: a retrospective, epidemiological, multicenter, case only study. PLoS One 2016;11:e152312. 